\title{
VOCÊ TEM FOME DE QUE? A EXPERIÊNCIA ARTÍSTICA COMO ELEMENTO ESSENCIAL DA CIDADE*
}

\author{
What are you hungry for? Artistic experience as an essential element of the city \\ ¿De que tienes hambre? La experiencia artística como elemento esencial de la ciudad \\ Vitor Silva Freire \\ Universidade de São Paulo (USP), Brasil \\ vifreire@gmail.com \\ DOI: https://doi.org/10.18472/cvt.20n3.2020.1885 \\ Redalyc: http://www.redalyc.org/articulo.oa? \\ $\mathrm{id}=115464747010$
}

Recepción: 15 Noviembre 2020

Aprobación: 17 Diciembre 2020

\section{Resumo:}

O artigo tece uma reflexão teórica que visa identificar a relevância da experiência artística na criação de vínculos sociais e apropriação do espaço urbano. De forma específica, tem o objetivo de analisar o significado da popularização das lives musicais pela internet como opção de entretenimento em meio ao isolamento social provocado pela pandemia de Covid-19 em 2020. Propõe-se que essa modalidade pode significar mais do que o acesso a um conteúdo artístico, representando uma simulação ou aproximação de uma experiência de outra ordem, e evocando a necessidade da participação presencial em eventos musicais que se configuram como parte da expectativa sobre o que a cidade oferece a seus cidadãos. A estrutura do texto utiliza como um gatilho reflexivo a delimitação de atividades essenciais e não essenciais durante a pandemia de Covid-19, valendo-se também de um estímulo musical a partir da canção Comida, da banda Titãs. O artigo utiliza uma bibliografia interdisciplinar, na qual se destacam contribuições do turismo urbano, hospitalidade e estudos sobre corpo. Complementa-se essa bibliografia com conteúdos de mídia e dados quantitativos do mercado musical.

Palavras-Chave: Entretenimento, Turismo Urbano, Live, Arte, Experiência.

\section{ABstract:}

The article makes a theoretical reflection that aims to identify the relevance of artistic experience in the creation of social bonds and the appropriation of urban space. Specifically, it aims to analyze the meaning of the popularization of musical lives on the internet as an entertainment option during the social isolation caused by the Covid-19 pandemic in 2020. It is proposed that this modality may mean more than access to artistic content, representing a simulation or approximation of an experience of another order, and evoking the need for face-to-face participation in musical events that are part of the expectation about what the city offers its citizens. The text structure uses as a reflexive trigger the delimitation of essential and non-essential activities during the Covid-19 pandemic, also using a musical stimulus based on the song Comida, by the band Titãs. The article uses an interdisciplinary bibliography, highlighting contributions from urban tourism, hospitality and body studies. This bibliography is complemented with media content and quantitative data from the music market.

KEYWORDS: Entertainment, Urban Tourism, Live, Art, Experience.

\section{RESUMEN:}

El artículo realiza una reflexión teórica para identificar la relevancia de la experiencia artística en la creación de vínculos sociales y la apropiación del espacio urbano. En concreto, tiene como objetivo analizar el significado de la popularización de las lives musicales en internet como opción de entretenimiento durante el aislamiento social provocado por la pandemia Covid-19 en 2020. Se propone que esta modalidad puede significar más que el acceso a un contenido artístico, representando una simulación o aproximación de una experiencia de otro orden, y evocando la necesidad de participación presencial en eventos musicales que son parte de la expectativa sobre lo que la ciudad ofrece a sus ciudadanos. La estructura del texto utiliza como detonante reflexivo la delimitación de actividades esenciales y no esenciales durante la pandemia Covid-19, utilizando también un estímulo musical basado en la canción Comida, de la banda Titãs. El artículo utiliza una bibliografía interdisciplinar, en la que destacan las aportaciones del turismo urbano, la hostelería y los estudios corporales. Esta bibliografía se complementa con contenido multimedia y datos cuantitativos del mercado musical.

Palabras Clave: Entretenimiento, Turismo Urbano, Live, Arte, Experiencia. 


\section{Bebida é ÁgUa/Comida É PASTo[1]}

Iniciamos este artigo com um estímulo musical - e, de certa forma, também um estímulo a algo que nos parece mais imediatamente essencial, um estímulo alimentar. Em 1987, a banda brasileira de rock Titãs (1987) lançou o álbum musical Jesus Não Tem Dentes no País dos Banguelas. Com intuito presumivelmente crítico, já a julgar pelo seu título, o álbum trouxe entre suas faixas uma música intitulada Comida, que marcou alguns conhecidos versos no repertório popular da época. "Você tem fome de quê?", perguntaram seus compositores, para complementar que "A gente não quer só comida/A gente quer comida, diversão e arte" (Antunes, Britto, \& Fromer, 1987).

Deste início talvez ainda pouco esclarecedor (mas não aleatório, garantimos), saltamos para o contexto em que este artigo é escrito. No início de 2020, foi confirmado que o surto do vírus Sars-CoV-2, comumente apelidado apenas de coronavírus, era uma Emergência de Saúde Pública de Importância Internacional (Nações Unidas Brasil, 2020). Sem a necessidade de adentrarmos em detalhes de ciências biológicas que escapam a nosso alcance e interesse aqui, é possível presumir que qualquer leitor deste artigo saiba como essa emergência tornou-se uma pandemia global da doença Covid-19, que impôs ao mundo um severo número de mortes e sérias restrições ao cotidiano das cidades. $\mathrm{E}$ - o ponto que interessa a este artigo - passamos a encarar constantemente, em nossas conversas cotidianas, nas decisões governamentais, nas informaçóes trazidas pela mídia, a definição das chamadas atividades essenciais.

Neste contexto de pandemia, são consideradas atividades essenciais aquelas "indispensáveis ao atendimento das necessidades inadiáveis da comunidade" e que, se não atendidas, "colocam em perigo a sobrevivência, a saúde ou a segurança da população" (Decreto $\left.n^{\circ} 10.282,2020\right)$. Em suma, como medida para promover o distanciamento social e, por consequência, reduzir a disseminação de um perigoso vírus, tomase a decisão de que enquanto uma restrita parte das atividades habituais de uma cidade deve prosseguir (não sem os devidos cuidados sanitários), uma outra parte, por ora, deve esperar. Logo, tanto quanto para aquelas atividades definidas como essenciais (no Brasil, esta listagem oficial foi atualizada algumas vezes, não sem polêmicas), nossa atenção se volta também para aquelas que não fazem parte dessa lista.

Se tal contexto da pandemia causada pelo Sars-CoV-2 (ou novo coronavírus) é crucial para a composição deste artigo, desde já cabe fazermos dois esclarecimentos em relação às reflexões que virão a seguir, na tentativa de nos prevenir de qualquer má interpretação. O primeiro deles é que nossa intenção não é, de forma alguma, contrariar ou mesmo duvidar de decisóes que tenham sido tomadas por órgãos de saúde competentes - e que lidam com aspectos científicos que estão fora do nosso alcance, como já salientamos. Partiremos, sim, da questão da essencialidade, mas como um gatilho reflexivo a respeito dos significados do convívio dos cidadãos em um espaço urbano.

O segundo esclarecimento é que na proposta deste artigo não se encontrarão quaisquer tentativas de previsão de futuro, seja ele qual for, para um mundo pós-coronavírus. Partiremos, sim, da pandemia, mas não como ponto focal, e sim como evidência de aspectos do convívio dos cidadãos em um espaço urbano. Ou seja, por mais que compreendamos que um exercício de futurologia pode ser bastante tentador (e possivelmente útil) aos escritos de 2020, nosso olhar aqui tentará focar nos aspectos perceptíveis no presente, "único tempo em que é possível recordar o passado e imaginar um futuro possível”[2] (Fischetti \& Chiavazza, 2017, p. 129).

Ainda considerando o presente da escrita deste artigo, é válido notar que sua produção está intimamente relacionada a um contexto maior de pesquisa acadêmica. Seguindo seus estudos sobre Entretenimento, o autor deste texto é atual doutorando em Turismo com uma pesquisa focada no envolvimento do público com a experiência artística presencial.

Turismo e arte, duas origens do raciocínio que está por trás deste artigo acadêmico, figuram justamente no rol de atividades consideradas não essenciais durante o contexto da pandemia, tornando-se setores largamente prejudicados pela paralisação das suas ações que dependem especialmente da presença física do público participante. Afinal, poderíamos afirmar que sem elas, no fim, ainda sobrevivemos. 
Porém, uma delimitação a partir da simples condição para sobrevivência da espécie tem o poder interessante de nos forçar uma percepção sobre o que nos é, de fato, essencial. Assim, neste artigo tecemos uma reflexão teórica na qual procuramos identificar a relevância da experiência artística na criação de vínculos sociais e apropriação do espaço urbano. Em outras palavras, como a arte pode ser percebida como elemento essencial da vivência e convivência na cidade, parte do próprio ato de experienciar o espaço urbano. Para tal, de forma mais específica, pretendemos analisar o significado da popularização das lives musicais pela internet como opção de entretenimento em meio ao isolamento social provocado pela pandemia de Covid-19 em 2020 - tema que será melhor detalhado mais adiante.

Tomamos emprestada a inquietação de Krippendorf (2009, p. 3): "Todas as vezes eu quase tenho que me desculpar. O lazer e as viagens seriam apenas ninharias? Acredito que, na realidade, sejam assuntos maravilhosos: trata-se da felicidade de todos os indivíduos e do bem-estar de cada um na sociedade".

\section{NecEssidADE, DESEJo/NECESSIDADE, VONTADE/NECESSIDADE}

Se queremos tecer alguma reflexão sobre o que é essencial à vivência e convivência na cidade, precisamos entender o que, afinal, compõe este espaço. Braga (2007, p. 71) faz uma interessante revisão de literatura envolvendo diferentes abordagens na conceituação de espaço na Geografia, concluindo, como um ponto em comum, que ele "é o contínuo das relações sócio-espaciais". E, auxiliando o raciocínio proposto neste artigo, não deixa de ser interessante destacar dentre tais abordagens aquela desenvolvida por Brunhes, para quem "a Geografia estudaria o que chama de 'fatos essenciais", incluindo aí "os fatos essenciais ligados à cultura (relação homem/meio e formação do habitat) [itálicos nossos]” (Braga, 2007, p. 67). Não à toa, os elementos culturais locais têm se potencializado como evidente fator de diferenciação entre cidades (Vargas, 2013).

Em esforço semelhante de revisão de literatura, Abrão (2010, p. 48) percebe que o espaço geográfico "é resultado e condição da dinamicidade de relações que os homens estabelecem cotidianamente entre si, com a natureza e consigo mesmo" e que, assim como a definição de território, é um conceito cuja apreensão "não deve ser feita inseparavelmente da vida social de um grupo num determinado lugar” (Abrão, 2010, p. 62).

Aproximando essa conceituação com a proposta de fruição presente no Turismo, Azevedo, Mattos e Bartholo (2015), a partir das ideias de Yi-Fu Tuan, destacam o conceito de lugar, quando a vivência do espaço é preenchida por uma relação de afetividade e criação de vínculos, uma organização de significados que tem na cidade um centro por excelência.

Ou seja, partimos aqui da premissa de que a composição de uma cidade vai muito além de prédios e vias, das dimensões e formas geométricas de sua matéria concreta. Não tememos qualquer obviedade ao sublinhar que a identidade de uma cidade é composta pelo uso que as pessoas fazem desta mesma cidade, o que inclui suas relações de trabalho, moradia, subsistência, mas também - e não haveria por que desconsiderar este aspecto - suas práticas de tempo livre, o que nos coloca novamente no potencial de intersecção entre a análise da prática do turista e a do público da experiência artística.

Somando a nosso esforço de melhor compreendermos e organizarmos essa dinâmica que queremos observar, a concepção do turismo urbano destaca como seu sujeito "os 'consumidores de lugar', categoria que engloba aqueles que consomem, experienciam ou fruem a cidade, sejam moradores ou turistas" (Allis \& Vargas, 2015, p. 503).

Perceber a experiência do espaço urbano como um ato de consumo, vale dizer, não implica em qualquer redução à profundidade da prática. Pois percebemos que o próprio ato de comprar carrega também complexidade de significados semelhante ao que abordamos até o momento, considerando-se que "se posiciona dentro de um sistema de relações entre as pessoas para quem se compra e, também, para as pessoas com as quais se relaciona" (Vargas, 2016, p. 3).

Nisso, Vargas (2016, p. 3) distingue duas grandes categorias de compras. Se, de um lado, as chamadas “compras obrigatórias" prestam-se a satisfazer necessidades fisiológicas, de estabilidade, segurança e ordem, 

DA CIDAD...

"outras adentram o campo das necessidades hedônicas que trazem prazer, reconhecimento social e capacitação profissional". Levando em consideração a teoria sobre a satisfação de necessidades humanas propostas anteriormente por Abraham Maslow, não é desnecessário notar como a categorização das compras hedônicas de Vargas ainda carrega consigo o termo "necessidades".

$\mathrm{Ou}$ seja, ainda que nossa atitude de consumo mantenha uma ordem linear de açóes, impondo primeiramente as práticas que garantam nossa manutenção da vida, isto não significa necessariamente dizer que as práticas hedônicas figuram como supérfluas ou mesmo como menos essenciais na compreensão de nossa vivência e convivência na cidade.

Se a linha musical que percorre este texto é também uma metáfora alimentar, notamos como se expressa o filósofo Han (2019, p. 17) sobre o constante menosprezo às práticas do prazer e da diversão, considerandose especialmente sua dedicação aos estudos do Entretenimento (nos quais também nos inserimos): "É problemática a divisão estrita entre interior e exterior, entre coração e ânimo, entre essência e adorno ou entre sabor e tempero. O tempero não seria, afinal, parte essencial do sabor?”

\section{A geNTE NÃo QUER Só COMER/A gENTE QUER PRAZER PRA ALIVIAR A DOR}

Se há tal linha musical percorrendo de forma evidente todo o nosso texto é porque queremos convidar à sensação daquilo que será protagonista de nossa reflexão. O momento de pandemia do novo coronavírus em 2020 evidenciou o papel da música nas cidades de forma interessante.

Em nossos estudos sobre Entretenimento, sempre nos pareceu interessante prestar bastante atenção aos movimentos da imprensa, como uma forma de notar o burburinho em torno de assuntos que, muitas vezes, não são legitimados e abarcados da mesma maneira em outros círculos, além de nos ajudar a lidar com a extrema atualidade e efemeridade que são intrínsecas a este tipo de análise.

Em março de 2020, quando as populações de diversos países começaram a encarar regras de quarentena e isolamento social, apresentaçóes musicais nas janelas e varandas (para muitos, o único contato permitido com o mundo exterior à sua casa) começaram a ser presença constante em noticiários e redes sociais, com especial destaque aos episódios ocorridos em cidades da Itália, logo repetidos em outras localidades.

De maneira positiva e calorosa, a mídia destacou essas iniciativas e arriscou seus significados, considerandoas "um jeito de driblar o tédio" (G1, 2020), "animar a vizinhança" (RFI, 2020), "manter o astral elevado" (Worden \& Cantor-Navas, 2020, em tradução livre), “aumentar o moral” (BBC, 2020, em tradução livre), ou ainda "uma maneira divertida de passar o tempo" (UOL, 2020), "quebra [de] monotonia" (Zeppi \& Viñas, 2020) e "solidariedade" (Thorpe, 2020, em tradução livre).

No Brasil, igualmente afetado pela necessidade de quarentena, a relação entre a música e pandemia se fez presente. Atenta à nova dinâmica internacional, a Prefeitura de São Paulo propôs um edital de financiamento para apresentações artísticas realizadas nas janelas, percebendo no formato da iniciativa voluntária dos italianos uma possibilidade também de socorrer os profissionais do setor. Esse edital, logo suspenso por determinação do Tribunal de Justiça de São Paulo (Bergamo, 2020), conforme comentaremos mais adiante, não se limitava à dimensão de vizinhança das janelas musicais italianas, propondo que as apresentações fossem também gravadas e transmitidas pela internet.

E é justamente no ambiente online que a arte em tempos de pandemia passou a se tornar um fenômeno bastante relevante em terras brasileiras, merecendo nossa observação. O novo coronavírus consolidou então a palavra live no vocabulário brasileiro do entretenimento.

Como explica a Associação Brasileira de Música e Artes, a live musical é, basicamente, um show, porém "transferindo a experiência dos palcos para as telas" - e que se tornou uma modalidade particularmente forte no Brasil (Gonzales \& Lemos, 2020).

Diversas instituições ligadas ao fomento à atividade cultural profissional encorajaram o surgimento de empreitadas artísticas pela internet a partir do financiamento de produções. Incluem-se aí órgãos 
governamentais como a Fundação Nacional das Artes e seu Prêmio Funarte RespirArte (Funarte, 2020), entidades paraestatais como o Serviço Social do Comércio e seu edital Sesc Cultura ConVIDA! (Sesc, 2020) e instituições privadas como o Itaú Cultural (2020) e seu programa Arte como Respiro: Múltiplos Editais de Emergência.

Mas foram as iniciativas particulares de artistas famosos que colocaram as lives musicais em extrema evidência. Informações fornecidas pelo YouTube, plataforma digital que concentra a veiculação da maior parte das lives, atestam o recente crescimento de visibilidade dessa modalidade (uma possibilidade tecnológica existente há vários anos), destacando a maioria brasileira entre as lives mais acessadas na plataforma (Pacete, 2020).

O aumento do interesse do brasileiro pelas lives no período de pandemia é visualmente percebido nos gráficos da plataforma Google Trends (que recolhe os dados sobre as pesquisas efetuadas no buscador de internet Google) quando procuramos por termos como live, lives ou lives musicais e lives música, além das constantes referências em portais de notícias.

Bem, o exposto até aqui não chega a ser surpreendente. As pessoas estão trancadas em casa. Logo, suas possibilidades de deslocamento diminuíram radicalmente. Logo, a variação de paisagem em seu cotidiano agora se resume às paredes de sala, quarto, cozinha e banheiro. Logo, a interpretação de alguns parágrafos acima parece extremamente natural. Quando surge algum elemento capaz de nos tirar da monotonia, o agarramos com unhas e dentes. Em parágrafos ainda mais anteriores, pareceu que destacávamos a importância das atividades voltadas ao prazer, logo, buscar uma forma de diversão - o que inclui a fruição musical - é um impulso mais do que esperado. Mas será que podemos encontrar ainda outros significados neste fenômeno? Será que, de alguma forma, ele pode nos ajudar a refletir sobre o nosso convívio na cidade?

Nossa desconfiança a este respeito crescia quanto mais as notícias e comentários com os quais tomávamos contato anunciavam as lives ocorridas e que ainda estavam por acontecer como conteúdos em si, como valiosas chances de acessar e escutar a obra musical de variados artistas.

Mas precisamos levar em consideração que em 2020, para aquela porção da população que possui acesso à internet (e é dentro dela que está o público das lives), é difícil sustentar que faltavam conteúdos de entretenimento disponíveis. Para falar apenas do universo da música, é possível tomar contato com, literalmente, milhões de músicas, inclusive gratuitamente, em populares plataformas digitais de streaming como Spotify (2020) e Deezer (2020).

Se a questão é o oferecimento de estímulo visual em conjunto com a música, os canais oficiais no YouTube dos artistas com maior número de visualizações de suas lives (Andrade, 2020) já possuíam grande quantidade de vídeos musicais, como videoclipes e gravaçóes de shows, planejados e produzidos de forma especializada para a apreciação audiovisual - em alguns casos, ultrapassando uma centena de produções oferecidas, com acesso gratuito, pelo mesmo artista.

De fato, retomando o exposto pela Associação Brasileira de Música e Artes, a pandemia não nos trouxe exatamente uma novidade nem na conceituação da experiência musical, nem mesmo na utilização da tecnologia (Gonzales \& Lemos, 2020). Ainda assim, um fenômeno relevante está à nossa frente. Logo, se não traz o novo, e se não arriscaremos uma proposta de futuro, o que a pandemia evidencia já de nosso presente?

Por isso, fomos fortalecendo a desconfiança de que janelas e lives não nos traziam um conteúdo em si, mas aproximações e simulações de uma outra experiência que nos habituamos a vincular ao espaço da cidade.

\section{A genTE NÃO QUeR Só COMIDA/A genTE QUER SAÍdA PARA QUALQUER PARTE}

A evidência da iniciativa virtual como uma saída encontrada para a continuidade da oferta musical nos coloca diante da necessidade de sublinharmos, ainda que brevemente, qual é o peso que a música ao vivo pode ter na vida da cidade, inclusive em termos econômicos. 
Para isso, focamos na cidade de São Paulo, lugar em que vivemos e onde se concentra nossa atual pesquisa acadêmica. E, considerando aqui nossa prévia experiência profissional, é válido salientar de antemão a costumeira dificuldade na obtenção de indicadores precisos e dados oficiais relacionados às atividades culturais profissionais de qualquer natureza.

O Data Sim (2018) realizou em 2018 uma pesquisa sobre os espaços de música ao vivo na cidade de São Paulo. A pesquisa projetou que 300 espaços previamente mapeados que ofertavam apresentações musicais ao vivo (e que não representam a totalidade da oferta da cidade) seriam responsáveis por um volume de 10.200 atrações mensais na cidade. Se consideramos este um número relevante, mais uma vez destacamos que este volume tende a ser largamente amplificado se tivéssemos condições de somar aí a diversidade de locais não especializados (como aqueles voltados à gastronomia) que também oferecem, inclusive de forma irregular, apresentações de música ao vivo.

A pesquisa ainda sugere que essa identidade de ampla oferta musical da cidade poderia ser ainda mais trabalhada para um reconhecimento público que traria benefícios à atividade turística (Data Sim, 2018), o que parece bastante pertinente considerando que o contínuo fluxo entre a cidade e suas vizinhas do interior paulista, incluindo a facilidade de vias de conexão, é uma condição que "facilita e estimula a vinda de visitantes em busca de atividades de lazer (visitas a museus e teatros, fruição da vida noturna e a gastronomia etc.)" (Allis \& Vargas, 2015, p. 512).

Em termos econômicos, a pesquisa do Data Sim obteve respostas de 49 espaços de música ao vivo na cidade de São Paulo que aceitaram fornecer suas informações de faturamento, chegando a um valor anual de mais de 69 milhões de reais. Considerando os 86 espaços que participaram de alguma forma da pesquisa (dentre os 300 originalmente mapeados), projetou uma estimativa de receita anual de aproximadamente 195 milhões de reais. E ainda, a partir da totalidade de espaços mapeados, a pesquisa projetou um total de 7.500 postos de trabalho envolvidos diretamente (Data Sim, 2018).

Não pretendemos cansar o leitor repetindo seguidas vezes a observação de que o universo ofertante de música ao vivo no espaço paulistano é muito maior. Mas enquanto o extremo detalhamento da pesquisa não é nosso foco aqui (e, afinal, ela pode ser analisada na íntegra em sua fonte original), esses dados nos servem como ilustração do quanto essa atividade diretamente ligada à fruição dentro dessa cidade carrega em si um vasto potencial econômico.

Infelizmente, um artigo elaborado em tempos de pandemia não pode se perder em otimismos, e precisa se deparar também com as fragilidades impostas pela situação. Nisso, tecemos uma ponte para o relatório que o mesmo instituto gerou sobre os impactos do coronovírus no mercado musical brasileiro. Não podemos traçar aqui nenhum paralelo direto, uma vez que esta segunda produção não está restrita nem à cidade de São Paulo nem à especificidade do segmento de música ao vivo. Mas é relevante apontar que, considerando as 536 empresas envolvidas com o setor musical que responderam à pesquisa (foram invalidadas quase 900 respostas de participantes que não possuíam um CNPJ, o que foi acuradamente apontado no próprio relatório como um sintoma da fragilidade do setor), chegou-se a um prejuízo estimado de mais de 480 milhões de reais (Data Sim, 2020). Tal dado, aqui, serve como uma nova ilustração do quanto esta atividade, se anteriormente apontada como detentora de potencial, agora se percebe em pedido de socorro.

Esta nossa seção apenas nos obriga a lembrar, paralelamente à reflexão dos significados das lives para o público - nosso maior foco neste texto, que, antes de comemorarmos a resiliência, reinvenção e criatividade dos profissionais das artes na elaboração de novos formatos, o que temos à nossa frente é uma tentativa de sobrevivência. Seguindo nosso comentário anterior a respeito dos conteúdos previamente existentes, elaborados de forma especializada, para fruição digital, esse novo fenômeno é uma tentativa de sobrevivência baseada no improviso - e como poderia deixar de ser, mediante um desafio impossível de prever?

É realmente possível que as lives tornem-se um novo formato a ser dedicadamente explorado pelo mercado musical. A se julgar pelos exemplos que temos até agora, essa seria uma realidade mais palpável aos grandes agentes de mercado. Àqueles de menor repercussão, incapazes de aparecer na grande mídia da mesma maneira, 
provavelmente encontram possibilidades virtuais agora na estreita relação com instituições direcionadas ao fomento cultural. Nada garante, porém, que em outros tempos estas mesmas instituições continuem apoiando iniciativas virtuais. É de fato uma possibilidade, mas essa definição está delegada ao tempo futuro e, por enquanto, essa previsão nos escapa. Mas, no presente, o que temos com as lives parece ser um substituto, uma simulação ou aproximação de uma experiência de outra ordem.

\section{A genTE NÃo QUER Só COMER/A GENTE QUER COMER E QUER FAZER AMOR}

O que, para além do conteúdo, a experiência artística ao vivo e presencial - neste caso, na especificidade da experiência musical - pode representar? Parece óbvio e evidente que em uma apresentação musical ouvimos... música. Mas há algo mais que sentimos, percebemos, vivemos em um evento dessa natureza?

Rhormens (2018) dedicou-se a compreender as relações sociais envolvidas nas apresentações musicais, notadamente no segmento de música sertaneja - e é este, justamente, que figura entre aqueles que mais têm recebido atenção de público no formato das lives pela internet.

Pelo que Rhormens (2018, p. 184) nos sugere, se propomos aqui olhar para a música (o acontecimento da apresentação) além da música (a obra artística executada), não tratamos apenas de aspectos adicionais e coadjuvantes que envolvem o público participante, como se fossem outras camadas que acidentalmente ocorrem durante a fruição musical. Mas tratamos - e isso modifica sensivelmente nossa análise - do próprio fator de motivação que levou a pessoa até o evento musical em primeiro lugar. Pois "a interação que os indivíduos têm entre si nestes eventos e as relações que são estabelecidas nestes lugares são fatores que levam as pessoas a frequentarem estes espaços".

Parece que, mais do que artístico, tratamos de um acontecimento social. Uma vez que nossa análise está tão mergulhada no universo da música quanto no da internet, vale a pena notar que a rede social Facebook encomendou uma pesquisa sobre os frequentadores de shows de música em diversos países (incluindo o Brasil). O significado social do evento volta a chamar a atenção quando a maioria dos entrevistados (63\%, no caso do Brasil) diz que passar um tempo com outra pessoa importante para eles "pode levá-los a comprar um ingresso [para um show], mesmo quando 'realmente não conhecem ou amam o artista"' (Kantar Profiles, 2019).

Isso não significa que essas pessoas são indiferentes ao conteúdo artístico, é bom frisar, mas que veem outras importâncias nesta experiência, e até estão dispostas a encontrar um conteúdo estranho, se acompanhadas de alguém familiar (no sentido de vínculo e proximidade, não de parentesco). Há uma disposição para o extraordinário, podemos dizer - quando a companhia vale a pena.

Aliás, a mesma pesquisa coloca que ir a um show acompanhado é hábito da destacada maioria ( $95 \%$, no caso brasileiro) dos frequentadores. Para Rhormens (2018, p. 184), na sua análise do segmento sertanejo, a relação social envolvida com o evento musical não é só aquela previamente existente, mas há também as relações que se espera constituir a partir do próprio evento, pois considera que as músicas sertanejas, "pelo fato de serem dançantes, facilitam a aproximação das pessoas, o estabelecimento de amizades, a paquera, entre outras relações sociais".

"Diferença, complexidade, estranheza" configuram-se como aspectos da experiência urbana (Sennett, 2006, p. 24). E o uso do termo extraordinário, algumas linhas antes, não se deu por acaso. É resultado de nosso aprendizado a partir do contato com os estudos sobre turismo urbano, que nos ajudam "quando tratam de entender as intervenções urbanas nas grandes cidades, que se convertem em espaços de consumo e fruição tanto para moradores, quanto para turistas" (Allis \& Vargas, 2015, p. 499). No tipo de pesquisa que empreendemos, essa é uma contribuição valiosa, pois entendemos que na fruição do espaço urbano, "os comportamentos espaciais dos turistas e dos moradores são, em grande medida, semelhantes e se confundem" (Allis \& Vargas, 2015, p. 499). 

DA CIDAD...

Essa é uma importante porta que se abre para unirmos forças no entendimento da busca por diversão no contexto das cidades, e ampliarmos a maneira como percebemos a ida à experiência artística. Pois se os movimentos do público da experiência artística originados na mesma cidade e aqueles que partem de outro território, assim como os movimentos do público da experiência artística que exigem uma ou várias pernoites em outra cidade e aqueles que se limitam a uma prática de "bate-e-volta", podem guardar consideráveis diferenças, também guardam valiosas semelhanças. E tais semelhanças concentram-se justamente no ponto que mais nos interessa, que é o significado da experiência que estão a buscar.

Nisso, o olhar do turismo nos ajuda a evidenciar uma busca pelo extraordinário, pela procura por momentos de prazer, por uma experiência sensorialmente diferente, não encontrada na vida cotidiana (Allis, 2014). É dessa possibilidade que a experiência artística, quando enxergada por esse viés, pode ser um exemplar. Mais do que um momento de mudança de latitude e longitude (que também pode ocorrer, e não é desprezível), coloca-se como um momento de mudança - não ad eternum, mas delimitado e recortado no tempo e espaço - de ritmo, estímulos sensoriais, relações sociais e focos de atenção.

Uma colocação que, não por acaso, se liga ao olhar do Entretenimento, campo habitualmente entendido como adjacente aos estudos de Turismo, o mesmo que assumimos desde o início do artigo. Afinal, a partir de um evento organizado para o deleite de uma audiência, o entretenimento representa a busca das pessoas por um divertimento intenso que faça "esquecer os índices e estatísticas que, em sua maioria, jogam contra seus sonhos e seus desejos” (Trigo 2003, p. 153).

\section{A gENTE NÃo QUER Só DINHEIRo/A GENTE QUER INTEIRO E NÃo PELA METADE}

Se uma live de internet carrega todo um potencial de diversão, é importante percebermos como a experiência desse formato, em relação à experiência presencial no evento musical, é essencialmente diferente. No contato com o seu computador, televisão ou celular, a paisagem à sua volta se mantém. Se o conteúdo acessado (a performance do artista) pode trazer algo de novo, o espaço experienciado é o mais cotidiano possível - em especial, em um momento de quarentena e permanência forçada no ambiente doméstico.

Não são poucas - e nem novas - as análises que diminuem o valor da arte quando ela é colocada nos termos que encontramos no entretenimento doméstico - mediada por um recurso tecnológico ao invés da presença física, em um formato reproduzível ao invés de um exemplar único, acessível de forma massiva ao invés do contato mais exclusivo.

É provável que um dos exemplares mais conhecidos - e reconhecidos - seja encontrado em Walter Benjamin (2012, p. 17), que crava que "mesmo à mais perfeita reprodução falta um elemento: o aqui e agora da obra de arte - sua existência única no local onde se encontra". Evidenciando um momento em que tal discussão estava em voga (quem sabe quantas outras reflexões semelhantes poderão surgir neste momento em que a pandemia se traduz em uso forçado da tecnologia), Franz Kafka, escritor da mesma geração, foi por caminho parecido. Como nos conta Han (2019, p. 164), "mídias são, para ele [Kafka], fantasmas que derealizam [de-realisieren] o mundo, que tiram dele toda apreensi-bilidade [Fass-barkeit]".

Embora compreendamos completamente o intuito - e o contexto - de reflexões como essas, não é o caminho que seguimos aqui. Por isso, abrimos espaço para a ponderação proposta por Figueiredo (2009), em uma reflexão já consideravelmente mais atual:

Para as correntes de pensamento que encaram o virtual como produtor de uma experiência menor é bom lembrar que experiências são experiências, seja qual for o tipo e a intermediação. Para aqueles que enaltecem essas novas formas de experiências e de realidades, é bom lembrar que a experiência concreta continua um grande sucesso, ou, como diz o senso comum, sentir é viver, e a experiência da vida é insubstituível (Figueiredo, 2009, p. 535).

Nem é nossa proposta hierarquizar a qualidade das experiências, nem achamos que este juízo teria algum valor para além de mera opinião nossa - tão válida quanto qualquer outra, e tão sujeita ao gosto 
quanto qualquer outra. Nos interessa, sim, a diferença entre as experiências, o que torna preciosa a última palavra da citação anterior, quando se fala do insubstituível. Por isso, falamos anteriormente de simulações, aproximações - mas não substituições.

Não fazemos aqui nenhuma objeção a empreitadas artísticas virtuais e nem deixamos de enxergar nelas potências e possibilidades. Mas, se nos propusemos antes a olhar a música para além da música, também olhemos as lives para além das lives. Considerando o que expusemos até aqui, acreditamos que a repercussão das lives como temos percebido neste momento é uma forma de evocar uma experiência presencial que se espera obter na cidade, vinculada diretamente ao contato com espaços externos, com vínculos sociais, com a mudança no entorno.

Lembrar de algo, sobretudo em momentos de perda, de saudade, não é sem valor - e às vezes é tudo o que temos. Se a existência da cidade depende de nosso convívio, podemos arriscar que durante um período de pandemia e isolamento social, a cidade, de certa forma, apesar de sua concretude continuar intacta, está em suspensão. Se a cidade é formada por vínculos que construímos, sentiremos falta dessa atividade. Se a experiência artística (neste caso, em especial, a musical) é também responsável por parte desse convívio e vínculos, uma experiência de simulação ou aproximação da anterior experiência presencial é investida de um significado muito maior do que seu conteúdo em si.

Mas a experiência lembrada não é exatamente a experiência vivida. E a sensação (estamos, afinal, em um campo de subjetividades) de que ela não é suficiente talvez possa ser fortalecida pelos desenhos dos mesmos gráficos do Google Trends que mencionamos antes. Todos eles oferecem uma forma quase triangular que, se teve um pico, já demonstra considerável descendência, ou mesmo pela queda de audiência percebida nas apresentações dos artistas mais visualizados (Ortega \& Neves, 2020). Porém, esse caminho quantitativo de análise pode ser bastante frágil neste momento. Demandaria mais tempo de análise, dados que ainda não possuímos e, provavelmente, maior passagem de tempo para medirmos um fenômeno tão recente e sujeito a tantas variações. Muito mais adequado a este artigo é seguirmos por um viés de reflexão teórica, procurando compreender um pouco mais o que o substituto virtual parece evocar, mas não alcançar.

A nossa presença no espaço da cidade - e nossa percepção e apropriação deste mesmo espaço - não se dá apenas de forma racional. Longano (2020) pesquisa o corpo em relação com as artes e nos sugere outros referenciais para lidarmos com a presença no espaço, destacando que os sentidos não são só pessoais, mas também são construídos socialmente.

O ponto aqui não é de exclusão, mas de soma, uma vez que o problemático seria "exatamente corroborar esse entendimento de que ou sentimos ou pensamos" (Longano, 2020, p. 195). Para refletirmos sobre o que completa uma experiência presencial, não devemos nos limitar à racionalidade, tampouco devemos nos deixar enganar por um demasiado foco no sentido da visão que o espaço urbano, tão ligado em nosso imaginário à noção de paisagem, delimitações de vias e terrenos, alturas de construções, marcos de localização, etc., pode nos sugerir. Quando estamos presencialmente na cidade - e não contemplando-a por uma tela - estamos nela por inteiro.

Não há nenhuma inovação nesta noção, vale dizer. Pires (2005, p. 30), em seus estudos sobre corpo, destaca uma relação direta dos sentidos com a cidade quando lembra que "a arquitetura e o urbanismo gregos desenvolveram-se no sentido de projetar ambientes e criar espaços nos quais o cidadão preservasse sua capacidade de percepção", uma proposta espacial conectada a um entendimento de liberdade "pelo privilégio de expor-se inteiramente". Embora, na contemporaneidade, Sennett (2006, p. 15) critique "a privação sensorial a que aparentemente estamos condenados pelos projetos arquitetônicos dos mais modernos edifícios", encorajado ou reprimido, é o corpo - logo, a razão e os sentidos - que experiencia o espaço.

Na nossa apropriação do espaço, o antropólogo Ingold (2015, p. 87) escorre o foco dos olhos até os pés, pois é "em contato com o chão (embora mediados pelo calçado), que estamos mais fundamentalmente e continuamente 'em contato' com o nosso entorno". Como fruir a cidade sem pisar a cidade? Pensar em pés, aliás, só nos coloca a divagar sobre as danças e saltos que tanto marcam os shows que presenciamos... E há 

DA CIDAD...

algo mais aí, pés que estão acompanhados pelos de outras pessoas (às vezes, na confusão, se sobrepondo, por que não?), uma copresença impossível de se ignorar - mesmo quando se quer. Uma dinâmica, portanto, de difícil repetição no chão do quarto ou da sala de estar.

Vargas (2013) reconhece as possibilidades interessantes trazidas pela busca do substituto virtual - o que, entretanto, não significa que se chegará onde se espera:

Nesta busca, o espaço criado pelos computadores pode existir em qualquer lugar e não é limitado por nenhum contexto cultural ou físico. Com o software adequado e uma habilidade no teclado, qualquer um pode escapar do real no território da mídia. É difícil imaginar um mundo onde a experiência sensual e tangível é substituída pelo pensamento, um mundo onde o corpo é redundante (Vargas, 2013, p. 196).

\section{A GENTE NÃO QUER Só DINHEIRO/A GENTE QUER DINHEIRO E FELICIDADE}

Apesar do que escrevemos até aqui, ainda se faz necessário reclamar a importância da arte na cidade - ou, melhor dizendo, a essencialidade da arte na cidade. Anteriormente, neste mesmo texto, nos comprometemos a retomar o episódio da suspensão, pelo Tribunal de Justiça de São Paulo, do edital Janelas de São Paulo, proposto pela prefeitura paulistana.

A instabilidade de mecanismos de financiamento à cultura está longe de ser assunto novo ou surpreendente, tampouco nos interessam aqui as tecnicalidades jurídicas que podem ou não justificar a suspensão do edital, assim como não nos cabem considerações sobre a qualidade das intenções dos envolvidos. Vale a mais a pena observarmos algum detalhe do discurso.

À proposta da Prefeitura de São Paulo de destinar dez milhões de reais para que artistas fizessem apresentações artísticas em suas janelas - posteriormente compartilhadas pela internet, seguiu-se um pedido de liminar traduzindo essa ideia como absurda, em especial porque na Itália uma iniciativa artística semelhante (e que serviu de inspiração a esse mesmo edital) tinha ocorrido de forma voluntária (Bergamo, 2020). No mesmo direito, pedimos licença para traduzirmos essa tradução: a arte é muito bem-vinda; mas se precisarmos pagar os artistas, nem tanto.

Ao pedido, seguiu-se a avaliação e a referida decisão do juiz, suspendendo os efeitos do edital enquanto a Prefeitura não desse explicações "sobre a questão orçamentária e detalhes da destinação dos valores, bem como a garantia declarada e demonstrada de que não há risco de que, em virtude da pandemia, esses valores possam vir a faltar a serviços essenciais [itálico nosso]" (TJSP, 2020).

Esse edital não foi o único do tipo lançado pela Prefeitura de São Paulo durante o período de pandemia, e outro teve destino semelhante. O edital Teatros e Centros Culturais na Rede, com a proposta de financiar apresentações artísticas a serem transmitidas pela internet, foi também suspenso pelo Tribunal de Justiça após uma ação popular. Também não faremos aqui a análise sobre os critérios e procedimentos encontrados nas normas do edital. Interessa-nos mais a observação de outro detalhe do discurso. $\mathrm{Na}$ ação popular, seu autor questionava a "essencialidade em caráter emergencial de destinar verba pública para artistas gravarem vídeos sem qualquer critério em suas casas para enfrentamento da calamidade pública decorrente da covid-19, em detrimento de todas as categorias de trabalhadores do país [itálico nosso]” (Martins, 2020).

Quando observa a ida ao evento musical pelo âmbito das relações sociais, Rhormens (2018, p. 185) soma como um elemento relevante, inclusive, o momento de se arrumar para o evento, aplicando no corpo um vestuário fora do habitual, afirmando que "esse ritual, os indivíduos gostam e o fato de poderem se comunicar com o outro faz com que essa preparação de si também seja cultural".

A escolha da palavra ritual sublinha o aspecto simbólico da atividade. $\mathrm{O}$ que ganha uma conotação interessante quando Camargo (2015, p. 55) reflete que, "entretanto, é extremamente importante referir que nossa cultura odeia o ritual, o rito e a ritualidade, pois escapam do domínio da razão”.

Nos parágrafos escritos acima, talvez estivéssemos, de fato, falando sobre a regularidade daqueles editais, sobre gestão orçamentária e sobre uma emergência sanitária; ou talvez - e essa é a nossa sugestão - 
estivéssemos falando de algo além, de uma difundida percepção social que conclui que a arte não é um elemento realmente essencial às nossas vidas. Muito antes da existência desta pandemia, a métrica para gastos com a atividade cultural tendo como base a quantidade de hospitais ou vacinas que poderiam ser comprados com o mesmo dinheiro, já era prática recorrente.

Assim, tirar a experiência artística da esfera do simples alívio do tédio, e perceber como ela integra uma expectativa do que é experienciar cidade, não é um esforço sem importância. Pois o valor que se dá à arte configura-se como o valor que se dá às ações, interações e vínculos das pessoas no espaço urbano. Não só reconhecendo tais elementos subjetivos como, em si, responsáveis por estabelecer a própria identidade da cidade, mas também percebendo seu potencial para que essa seja, enfim, uma boa cidade.

Camargo (2015, p. 55) nos lembra (ao lembrar, ele mesmo, das contribuições de Canclini, Castells, Santos, Tuan, Magnani e Augé) tal importância do vínculo para essa configuração espacial, notando que "os indivíduos criam ilhas de relações primárias, formas seletivas de sociabilidade em meio à sensação de anonimato nas metrópoles".

A experiência artística é, justamente, uma dessas formas de sociabilidade constantemente presentes nos hábitos de uma grande cidade - que, de tão habitual, talvez esqueçamos a importância com que é revestida. E, no caso do foco deste artigo, "a música é mediadora de encontros e emoções nos diferentes espaços onde elas são tocadas" (Rhormens, 2018, p. 48).

Pensar não apenas na vivência e convivência na cidade, mas em boas vivência e convivência na cidade, nos conduz, já ao fim de nossas reflexões, à noção de cidadania, que, por sua vez, conduz à noção de hospitalidade no espaço urbano (Severini \& Vargas, 2016). E se parece interessante dizer que uma cidade boa é uma cidade hospitaleira, é importante lembrar que essa qualidade não será alcançada por seus elementos materiais. Pois Camargo (2015, p. 49) nota que "a hospitalidade diz respeito à relação entre seres humanos", assim "uma cidade não é hospitaleira ou inospitaleira: os que (não) planejaram adequadamente o espaço urbano, aqueles com os quais nos relacionamos é que (não) o são".

O não empregado no parágrafo anterior não é mero acaso. Pois - e voltamos ao fato de que um artigo elaborado em tempos de pandemia não tem como se perder em otimismos - "designar a hospitalidade como virtude é considerar que o panorama social é marcado pela sua ausência" (Camargo, 2015, p. 51). A cidade, de antemão, talvez não seja (ou esteja) como gostaríamos. Mas a partir das relações que estabelecemos dentro do espaço urbano, no entanto, ela pode mudar - não seria isso essencial?

\section{REFERÊNCIAS}

Abrão, J. A. A. (2010). Concep̧̧ôes de espaço geográfico e território. Sociedade e Território, 22(1), 46-64.

Allis, T. (2014). Viajantes, visitantes, turistas... em busca de conceitos em um mundo urbano. Caderno Virtual de Turismo. Edição especial: hospitalidade e politicas públicas em turismo, 14, 23-38.

Allis, T., \& Vargas, H. C. (2015). Turismo urbano em São Paulo: reflexões teóricas e apontamentos empíricos. Turismo em Análise, 26(3), 496-517. https://doi.org/10.11606/issn.1984-4867.v26i3p496-517

Andrade, V. (2020, Abril 24). Ranking de lives: Brasil tem 4 das 5 maiores audiências mundiais do YouTube. Notícias da $T V$. Recuperado em Novembro 15, 2020, de https://noticiasdatv.uol.com.br/noticia/mercado/ranking-de-l ives-brasil-tem-4-das-5-maiores-audiencias-mundiais-do-youtube-36059

Antunes, A., \& Britto, S., \& Fromer, M. (1987). Comida. [Gravado por Titãs]. In Titãs: Jesus Não Tem Dentes no País dos Banguelas [LP]. WEA.

Azevedo, A., \& Mattos, F., \& Bartholo, R. (2015). Entre o espaço e o lugar: considerações sobre o Campo de Santana e a Casa de Deodoro na dinâmica cultural e turística da cidade do Rio de Janeiro. Caderno Virtual do Turismo, 15(3), 251-262.

BBC. (2020, Março 14). Coronavirus: Italians sing from their windows to boos morale. Recuperado em Novembro 15 , 2020, de https://www.bbc.com/news/av/world-europe-51886547 
Benjamin, W. (2012). A obra de arte na época de sua reprodutibilidade técnica. Zouk.

Bergamo, M. (2020, Março 22). Justiça suspende efeitos de edital que financia apresentações em janelas de SP. Folha de São Paulo. Recuperado em Novembro 15, 2020, de https://wwwl.folha.uol.com.br/colunas/monicabergam o/2020/03/justica-suspende-edital-que-financia-apresentacoes-em-janelas-de-sp.shtml

Braga, R. M. (2007). O espaço geográfico: um esforço de definição. GEOUSP - Espaço e Tempo, 22, 65-72.

Camargo, L. O. L. (2015). Os interstícios da hospitalidade. Revista Hospitalidade, XII, $42-69$.

Data Sim. (2020). Impactos da Covid-19 no mercado de música do Brasil. https://mailchi.mp/0091b2c20376/covid1 9_impacto_musica_brasil

Data Sim. (2018). O mercado da música na cidade de São Paulo - parte 1 - espaços de música ao vivo. https://mailchi .mp/simsaopaulo.com/aovivoparte01

Decreto $n^{\circ}$ 10.282, 20 de março de 2020. Diário oficial, Brasília, Seção 1, Edição Extra H, p.1. (2020). https://www2 .camara.leg.br/legin/fed/decret/2020/decreto-10282-20-marco-2020-789863-republicacao-160192-pe.html

Deezer. (2020, Novembro 15). Sobre nós. https://www.deezer.com/br/company

Figueiredo, S. L. (2009). Turismo virtual? In: Panosso Netto, A., \& Ansarah, M. G. R. (Ed.). Segmentação do mercado turistico: estudos, produtos e perspectivas. Manole.

Fischetti, N., \& Chiavazza, P. (2017). Arte e ciencia en los márgenes de la academia. In: Alvarado, M., \& De Oto, A. (Ed.). Metodologias en contexto: Intervenciones en perspectiva feminista/poscolonial/latinoamericana. CLACSO.

Funarte. (2020, Junho 16). Prêmio Funarte RespirArte incentiva a produção artística nacional. https://www.funarte.g ov.br/artes-integradas/premio-funarte-respirarte-incentiva-a-producao-artistica-nacional/

G1. (2020, Março 13). De quarentena por novo coronavirus, moradores de cidades da Itália cantam nas janelas; veja vídeo. Recuperado em Novembro 15, 2020, de https://g1.globo.com/mundo/noticia/2020/03/13/de-quarent ena-por-novo-coronavirus-moradores-de-cidades-da-italia-cantam-nas-janelas-veja-video.ghtml

Gonzales, G., \& Lemos, R. (2020, Junho 8). Execução pública nas lives. ABRAMUS. Recuperado em Novembro 15, 2020, de https://www.abramus.org.br/musica/17682/execucao-publica-nas-lives/

Han, B. (2019). Bom entretenimento: uma desconstrução da história da paixão ocidental. Vozes.

Ingold, T. (2015). Estar vivo: ensaios sobre movimento, conhecimento e descrição. Vozes.

Itaú Cultural (2020, Abril 4). Arte como respiro: múltiplos editais de emergência - artes cênicas. https://www.itaucult ural.org.br/arte-como-respiro

Kantar Profiles. (2019). Concerts consumer journey study. https://www.facebook.com/business/news/insights/amp-u p-your-connections-with-concertgoers

Krippendorf, J. (2009). Sociologia do turismo: para uma nova compreensäo do lazer e das viagens. Aleph.

Longano, A. C. (2020). Seu corpo, sua arte: uma jornada artística-pedagógica-corporal. [Dissertação de mestrado, EACH/USP]. São Paulo, SP. Brasil. Biblioteca Digital USP.

Martins, A. (2020, Maio 21). Liminar suspende edital de cultura em SP para atividades online na pandemia. UOL. Recuperado em Novembro 15, 2020, de https://entretenimento.uol.com.br/noticias/redacao/2020/05/21/lim inar-suspende-edital-de-cultura-em-sp-para-atividades-online-na-pandemia.htm

Nações Unidas Brasil. (2020, Janeiro 30). OMS declara coronavírus emergência de saúde pública internacional. https:/ /nacoesunidas.org/oms-declara-coronavirus-emergencia-de-saude-publica-internacional/

Ortega, R., \& Neves, M. (2020, Maio 28). Lives perdem força: artistas voltam com audiência menor e indicam que pico da onda passou. G1. Recuperado em Novembro 15, 2020, de https://g1.globo.com/pop-arte/lives/noticia/202 0/05/28/lives-perdem-forca-artistas-voltam-com-audiencia-menor-e-indicam-que-pico-da-onda-passou.ghtml

Pacete, L. G. (2020, Maio 18). Adaptação em tempo real. Meio \& mensagem, p. 6.

Pires, B. F. (2005). O corpo como suporte da arte: piercing, implante, escarificação, tatuagem. Editora Senac São Paulo.

Rhormens, D. P. (2018). O negócio da música sertaneja no Brasil: tocando as emoçôes, as relaçóes, o corpo e a alma. [Dissertação de mestrado, PUC/SP]. Biblioteca Digital PUC-SP. https://tede2.pucsp.br/handle/handle/21560 
RFI. (2020, Março 14). Italianos cantam das janelas e criam concerto nacional para enfrentar quarentena do coronavírus. Folha de São Paulo. Recuperado em Novembro 15, 2020, de https://www1.folha.uol.com.br/equilibrioesaude/2020/03/italianos-cantam-das-janelas-e-criam-concertonacional-para-enfrentar-quarentena-do-coronavirus.shtml

Sesc (2020). Sesc Cultura ConVIDA!. http://www.sesc.com.br/portal/site/convida/

Sennett, R. (2006). Carne e pedra: o corpo e a cidade na civilização ocidental. Record.

Severini, V. F., \& Vargas, H. C. (2017). Rediscutindo hospitalidade urbana na lei de zoneamento de São Paulo de 2016. Revista Hospitalidade, 14(2), 1-27.

Spotify. (2020, Novembro 15). Sobre nós. https://www.spotify.com/br/about-us/contact/

Thorpe, V. (2020, Março 14). Balcony singing in solidarity spreads across Italy during lockddown. The Guardian. Recuperado em Novembro 15, 2020, de https://www.theguardian.com/world/2020/mar/14/solidarity-balcon y-singing-spreads-across-italy-during-lockdown

Titãs. (1987). Jesus Não Tem Dentes no País dos Banguelas [LP]. WEA.

TJSP. (2020, Março 22). Veja outras decisões da Justiça relacionadas à pandemia do coronavirus. http://www.tjsp.jus. $\mathrm{br} /$ Noticias$/$ Noticia?codigoNoticia $=60673$

Trigo, L. G. G. (2003). Entretenimento: uma crítica aberta. Senac São Paulo.

UOL. (2020, Março 13). De hino a Macarena: isolados, italianos saem às janelas para cantar juntos. UOL. Recuperado em Novembro 15, 2020, de https://noticias.uol.com.br/internacional/ultimas-noticias/2020/03/13/de-hinoa-macarena-isolados-italianos-saem-as-janelas-para-cantar-juntos.htm

Vargas, H. C. (2016). As motivações do consumidor definindo o tempo e o espaço das atividades de comércio e serviços [Apresentação de trabalho]. V Colóquio Internacional Sobre o Comércio e Cidade: uma relação de origem, São Paulo, SP, Brasil.

Vargas, H. C. (2013). Da arquitetura corporativa à cidade corporativa. In: Silva, G. P. A., \& Oliveira, L. A. (Org.). Arquitetura da cidade contemporânea: sobre raizes, ritmos e caminhos. Editora da UFSC.

Worden, M.; Cantor-Navas, J. (2020, Março 20). Italy and Spain lean on music to battle coronavirus lockdown blues. Billboard. Recuperado em Novembro 15, 2020, de https://www.billboard.com/articles/news/international/93 38885/italy-spain-coronavirus-music-lockdown

Zeppi, S.; Viñas, D. (2020, Maio 20). Músico quebra monotonia de moradores em prédios durante a quarentena. CNN Brasil. Recuperado em Novembro 15, 2020, de https://www.cnnbrasil.com.br/nacional/2020/05/20/musicoquebra-monotonia-de-moradores-em-condominios-durante-a-quarentena

\section{Notas}

[1] Todos os subtítulos deste artigo estão relacionados a versos da música Comida, mencionada no decorrer do texto, de autoria de Arnaldo Antunes, Sérgio Britto e Marcelo Fromer.

[2] Tradução livre de Anna Carolina Longano para o original "único tempo en el que es posible recordar el passado e imaginar un futuro posible"

* O presente artigo foi anteriormente aprovado para apresentação no XVII Seminário ANPTUR. 